See discussions, stats, and author profiles for this publication at: https://www.researchgate.net/publication/334677898

\title{
DESIGN FOR INCLUSION IN A LINGUISTICALLY AND CULTURALLY DIVERSE EUROPE: CHALLENGES IN THE DEVELOPMENT OF A VIRTUAL LEARNING ENVIRONMENT
}

Conference Paper · July 2019

DOI: 10.21125/edulearn.2019.1788

\section{CITATIONS}

0

5 authors, including:

Giulia Pastori

Università degli Studi di Milano-Bicocca

15 PUBLICATIONS 37 CITATIONS

SEE PROFILE

A. Alice Sophie Sarcinelli

Università degli Studi di Milano-Bicocca

23 PUBLICATIONS 4 CITATIONS

SEE PROFILE

Some of the authors of this publication are also working on these related projects:

Project CARE (Curriculum Quality Analysis and Impact Review of European ECEC) View project

Project Les enfants des couples de meme sexe en Italie et en Belgique View project
READS

22

Valentina Pagani

Università degli Studi di Milano-Bicocca

10 PUBLICATIONS 9 CitaTIONS

SEE PROFILE 


\title{
DESIGN FOR INCLUSION IN A LINGUISTICALLY AND CULTURALLY DIVERSE EUROPE: CHALLENGES IN THE DEVELOPMENT OF A VIRTUAL LEARNING ENVIRONMENT
}

\author{
A. Mangiatordi, G. Pastori, V. Pagani, A.S. Sarcinelli, L. Menegola1 \\ University of Milano-Bicocca (ITALY)
}

\begin{abstract}
The inclusive potential of digital technologies in educational contexts is well represented by multimodal communication: the use of different channels and strategies can lower barriers to participation and improve the overall quality of educational intervention. This paper discusses the issues and challenges encountered while developing a pilot multimodal learning platform in the context of the Horizon 2020 research project called ISOTIS (Inclusive Education and Social Support to Takle Inequalities in Society).

The overall aim of the ISOTIS project (www.isotis.org) is to address the challenges raised by the cultural and linguistic super-diversity of European society. It tackles inequalities and educational gaps at several levels and using a variety of research methods. One specific task of the project is centered on the design and development of a pilot VLE (Virtual Learning Environment). The platform ultimate goal is to enable children, parents and teachers to participate in various online activities and to communicate using different media (i.e., text, pictures, video and audio recordings), developing skills and acquiring knowledge about multilingualism and multiculturalism.
\end{abstract}

The main theoretical underpinnings of the project are design-based research intervention and Bronfenbrenner's bioecological model. Research interventions are being carried out in 8 European countries, focusing on understanding and highlighting the system of relationships among the actors involved at intervention sites (educators, practitioners, children, parents...). In all those countries the VLE was presented to participants and used as a means of improving awareness about the implications of linguistic and cultural diversity.

The choice of an Open Source software platform proved to be convenient especially on the data management side, but the implementation also had to face some problems - especially when it came to the integration of multiple features into a unique framework. Also, the application of Universal Design for Learning principles and guidelines introduced interesting elements, but this form of inclusive design required continuous and important efforts on both technological and educational levels and unveils some possible problems that should be taken into consideration.

Keywords: multilingualism, multiculturalism, inclusive education, Virtual Learning Environments.

\section{INTRODUCTION}

Despite several variables can affect achievement in education [1], and with some variability from country to country [2], educational opportunities of children are still strongly dependent on family origin [3]. The economic and social integration of immigrants and their offspring is linked to education in different ways. Differential access matters. In Europe, several immigrant groups from most diverse origin countries and continents face persistent educational disadvantages. Across EU member states, cases of internal inequalities in accessing education involve indigenous ethnic-cultural minority groups and native-born low-income working-class groups, as well as few transnational instances, such as that of Romani people. The quality and receptiveness of the education system is a condition both to educational achievement per se and to broadly meant social and cultural integration, and consequently, to the social mobility of children of disadvantaged families [4].

Western societies' cultural heterogeneity is constantly growing [5]. The concept of "super-diversity" is introduced, defined as a multilayered interweaving of ethnicity and religion, language and traditions,

\footnotetext{
${ }^{1}$ Section 1 was written by Giulia Pastori, Andrea Mangiatordi, Valentina Pagani, Alice Sarcinelli. Section 2 and Section 3 were written by Andrea Mangiatordi and Leonardo Menegola. All authors discussed the results and contributed to the final manuscript.
} 
cultural values and practices [6]. Within this framework, what lies at the heart of European superdiversity is education systems, and particularly classrooms [7], where increasing cultural diversity meaningfully interplays with linguistic diversity [8].

Extra- and intra-European immigration in its multiple declinations has been raising the number of children who have to learn the school language as a second language [9]. Such specific language gap provides them with persistent educational disadvantages, additional to the ones deriving from low socioeconomic status [10]. Beyond migration and the cultural and linguistic disparities it fosters, educational disadvantages also affect low-income, native-born families, often relating to shared cultural traits, such as beliefs and values, practices and ways of talking [11], [12].

Migrant families and low-income local ones often share the same neighborhoods, local services, and schools. This results in currently diffused dynamics of tension and rivalry between groups, which result in processes of inter-cultural separation and social fragmentation [13]. This sheds further light on both host and guest families' shared need for integration and acculturation [14], as a means to back tendencies to social and ethnic segregation, by raising and equalizing the quality of learning environments [15].

\subsection{The ISOTIS project}

In order to address these topics and provide research and intervention tools to improve the issues at stake with super-diversity and differential access to education - by combatting early arising and persisting educational inequalities and thus increasing inclusiveness - the ISOTIS program has been established. ISOTIS is a collaborative project funded by the European Union, including 17 partners from 11 countries. The programme aims at reinforcing the strengths and potentials of cultural and linguistic diversity deriving from migrant and non-migrant families, with a special regard to contexts of educational disadvantage, by giving them a voice in how to adapt early education systems and support services. ISOTIS has been doing so by producing evidence-based, contextualized and concrete tools and recommendations for:

- Creating safe and stimulating home environments for their children by underpinning culturally and linguistically diverse families and communities in employing their cultural and linguistic resources;

- Developing inclusive curricula and pedagogies for durably effective early childhood education in care centres and primary schools;

- Empowering and educating staff and institutional programmes' quality and inclusiveness;

- Promoting the coordination between support services to children and families;

- Favouring the development of policies for educational access equality and inclusiveness.

The project, which started in January 2017 and will continue until December 2019, addresses the multiple interdependences and environments affecting children's development, by proposing "collaborative online tools and apps for parents, classrooms and professionals involved in the lives of culturally and linguistically diverse families."

\subsection{Theoretical framework}

ISOTIS moves from Bronfenbrenner's bio-ecological systems model of personal development [16][18]. This model focuses on the "proximal processes" that occur at the physical, social and symbolic levels in the immediate environment of the individuals and involve types of practices that get increasingly complex over time, forming and fueling the micro-, meso-, exo-, macro-, and chronosystems. The proximal processes within microsystems - resulting from the interaction between individual characteristics and the physical, social and symbolic features of the system - can be evaluated qualitatively, quantitatively and content-wise [19] with respect to whether and how they drive dynamics of personal development.

The bio-ecological model provides a multifaceted framework to understand educational inequalities and to identify starting points for preventing or reducing them.

\footnotetext{
${ }^{2}$ http://www.isotis.org/about-isotis/project-information/, last consulted May 9, 2019.
} 
1 Through the proximal processes model it provides a tool to detect and analyze emerging developmental delays and educational disadvantages.

2 Through the micro- to macro-systems scheme it helps us spotting the effects on children's development of policies and institutional practices, as they are mediated by social agents, such as parents, teachers and peers.

3 Consequently, it links the resources (including time and motivation) social agents have to interact with the child - as well as their competences to provide particular contents for the child's development and learning - to the meso- and exo-systems they depend on. E.g., particularly relevant is the mutual coherence of quality and content between meso- and exosystems, especially in association with such major life course transitions and critical periods as 'home to preschool' or 'primary to secondary school' are.

4 This model represents an illuminating vantage point to observe and assess the polythetic interconnection between the different systems; their effectiveness in providing the quality, quantity and contents for optimal child development; and their embeddedness in - and mutual influence with - policies, institutions, and wider cultural and economic changes in the macrosystem.

Children from low socio-economic status families and from immigrant families tend to experience very early disadvantages in their cognitive, linguistic and socio-emotional development [20]-[22], and these disadvantages are often maintained - if not otherwise addressed - throughout the developmental trajectories and across individual educational careers [23], [24].

\subsection{ICT and Inclusive Education in the ISOTIS context}

In order to address the issues mentioned above and to comply with the stated objectives, the ISOTIS project includes the development, implementation and evaluation of inter-linked prototype programmes for parents, classrooms and education professionals, all based on the same Virtual Learning Environment (VLE) ${ }^{3}$. The VLE aims at stimulating interaction and collaboration among all stakeholders, and to foster a sense of belonging to a wider community. In compliance with the principles exposed so far, the VLE targets linguistically diverse contexts by building upon families' resources and supporting professionals to become competent in dealing with diversity.

This specific task of the project involves researchers from different teams and work packages; it also represents one element of continuity and sustainability for the time after the project ends, in the sense that it is planned that the platform will be maintained available online after the currently running pilot. The solutions adopted in the development phase will be documented in order to contribute to the diffusion of findings and strategies to a larger public of multilingualism and multiculturalism stakeholders.

Based on the issues discussed above, the ISOTIS team in charge of the design and development of the VLE chose to address multilingual and multicultural access issues by adopting the theoretical framework known as Universal Design for Learning (UDL) [25], [26]. This framework, inspired by the principles of Universal Design that were initially developed in the field of architecture by Ronald Mace [27], provides nine guidelines ${ }^{4}$ for educators and instructional designers, with specific advice about three main areas that correspond to brain networks:

1 Perception - linked to the recognition network, the part of the brain in charge of collecting and interpreting the information coming from the senses;

2 Strategic thinking - linked to the strategic network, in which responses to complex questions are elaborated, in activities such as solving a mathematical problem or writing a text;

\footnotetext{
${ }^{3}$ International coordinators of the VLE-related task are Giulia Pastori (PI of the Italian team) and Andrea Mangiatordi, from the University of Milano-Bicocca. The VLE task was carried out in three different work packages in the ISOTIS project. A transferable prototype of a Virtual Learning Environment was developed and piloted with parents focusing on activities to support engagement with the multiple language and cultural resources present in the lives of families with diverse backgrounds (WP 3 - D3.4 - Task leader: dr. Katharina Ereky-Stevens - University of Oxford); with teachers and classrooms, focusing on curricular activities to support multilingual development in early childhood and primary education (WP4 - D4.4 - Task leader: dr. Giulia Pastori University of Milano-Bicocca); and with (para)professionals in family support, care and education, focusing on professional development (WP5 - D5.4 - Task leader dr. Pauline Slot - University of Utrecht and Gil Nata - University of Porto).

${ }^{4}$ http://udlguidelines.cast.org/, last consulted May 9, 2019.
} 
3 Emotions and engagement - linked to the affective network, the part of the brain in charge of collecting and interpreting the information coming from the senses;

The main theory of UDL is that all people vary in the way they learn and in the way their brains process information and produce answers to pedagogical questions, and every learning process is also influenced by the level of engagement and in general by the affective sphere. UDL has already been connected to multicultural education, in the training of pre-service educators [28] or in secondary inclusive classrooms [29], but apparently not in primary or pre-primary school contexts, neither in working with families.

The following paragraphs present how and at what cost - in terms of encountered issues - the development of the ISOTIS VLE has addressed, solved or failed to solve problems connected with the super-diversity of its target population. The technological solutions that will be presented are not evaluated here in terms of measured performance or feedback from users: the focus will be on solutions that have "manifest usefulness" [30], where technology can represent a necessary factor that enables access to learning.

\section{METHODOLOGY}

In this section, we describe the ideas and methodologies that guided the design and development of the ISOTIS Virtual Learning Environment.

As a technological basis for the development of the platform, it was chosen to adopt Moodle, a modular Open Source software package designed to be customizable and to support communication, collaboration and tracking of learning processes, supporting an "anytime, anywhere learning" approach $^{5}$. This choice was mainly driven by the fact that Moodle is recommended in the related research literature for its features, especially in terms of communication tools [31] and on the basis of its compliance with educators needs [32]. There are also other motivations, in some cases more technical, in others more strategical: they are discussed in the following paragraphs and commented further in section 3.

\subsection{Openness, standardization and privacy}

Open Source Software (OSS) gives its users different rights, among which the possibility to study and improve it to fit specific needs in the best possible way [33]. Beyond that, the use of OSS is encouraged by many governmental and non-governmental institutions to leverage the possibility of reusing existing software, with benefits that are related both to a technical dimension (reliability, security, flexibility of use and performance) and to business (freedom from vendor lock-in, increased collaboration and innovation) [34].

For organizations that care about the privacy of their users, Open Source web applications like Moodle allow to build self-hosted, privacy-oriented environments: as the ISOTIS project involves different kinds of participants and addresses delicate topics, it was important to keep data management strictly under control. Moodle also supports different eLearning standards, such as $\mathrm{SCORM}^{6}$ and XAPI ${ }^{7}$, and provides a robust way to export content in order to make it easily transferable and reusable also after the end of the overall project.

\subsection{Usability and customizations}

As ISOTIS is based on the overall principle of inclusiveness, it was a priority to concentrate on the usability and accessibility aspects of the VLE. It was hence necessary to adopt a tool that allowed for high customization. Moodle is customizable mainly in two ways:

- It is extendable through plugins that add extra functionality or provide alternatives to built-in features: this aspect allowed to quickly add features on the basis of the pedagogical and content requirements that emerged as important during the process.

\footnotetext{
${ }^{5}$ https://moodle.org/, last consulted May 9, 2019.

${ }^{6} \mathrm{https} / / /$ adlnet.gov/research/scorm/scorm-2004-4th-edition/, last consulted May 9, 2019.

${ }^{7}$ https://www.adlnet.gov/research/performance-tracking-analysis/experience-api/, last consulted May 9, 2019.
} 
- It supports theming: not only the project aimed at the creation of the best possible user experience, but it also wanted to support multilingualism by facilitating the decoding of content by people with diverse needs and backgrounds. By a custom theme the platform could be enriched by additional features at the user interface level.

\subsection{Sustainability in the long run}

One last aspect that was relevant to our choice was the fact that the project aimed at being redistributable - together with the research results, the VLE implemented by ISOTIS could represent a valuable resource for schools and institutions that want to implement inclusive educational platforms for their users - which is in line with the OER philosophy and with the UDL principles discussed in section 1.3. The adopted technology had to be redistributable and reusable in future scenarios, in order to maximize the dissemination impact of the whole project.

\section{DISCUSSION}

The design and development phase of the platform involved installing and trying out many different Moodle plugins, in order to understand whether they could actually be useful for the final product or not, and if they had a reasonable usability level. Functionalities that were not available in Moodle core or in plugins were developed specifically for this intervention.

Following the UDL guidelines, a strong effort was made primarily for the reduction of barriers to perception and understanding of the platform content. Besides allowing the use of multiple communication channels, like videos or audio files, this effort involved adding support for multilingual content in a high number of languages (37 in total, based on the languages spoken by participants from 8 countries). Besides the user interface dimension, the development of the VLE had to carefully take into consideration privacy related issues. This was obviously necessary on a general note but was made even more important by the concomitant entry into force and application of the General Data Protection Regulation 2016/679/EU (GDPR).

The implementation choices in some cases revealed to be fruitful or at least convenient, but sometimes uncovered technical issues. Strengths and downsides of adopted solutions will be discussed in the following subsections.

\subsection{Positive experiences and strengths}

The main advantages that the adoption of Moodle brought to the project are related to privacy, flexibility and multimodal communication.

Privacy matters are not directly addressed by UDL guidelines, as they are connected to learning processes in what we see as a secondary way, yet they lie at the foundation of trustworthy and successful learning experiences. According to its official online plugin repository ${ }^{8}$, Moodle was enriched with a set of GDPR-related features via two plugins in September 2018. The two software packages, named "Policies" and "Data Privacy", respectively allow to

- "define various policy documents - site policy, privacy policy, intellectual property policy [...] and others as needed."

- provide "the workflow for users to submit subject access requests and for site administrators and privacy officers to process these requests."

The two plugins became part of the core of Moodle since its 3.5 version ${ }^{10}$, allowing easier implementation of their features in live websites. Activating them in the VLE meant having complete control over data access requests from participants, with the possibility to give permission to manage their data to different platform users according to their role in the project.

\footnotetext{
${ }^{8}$ https://moodle.org/plugins/, last consulted May 9, 2019

${ }^{9} \mathrm{https}: / /$ moodle.org/plugins/browse.php?list=set\&id=90, last consulted May 9, 2019

${ }^{10}$ At the time of writing, the current stable version of Moodle is numbered 3.6, while version 3.5 is the latest development version available.
} 
The Data Privacy plugin provides a way to generate dumps of data related to a single user in minutes in a standardized format based on XML, a feature that can also be useful for research purposes (i.e. for content analysis).

Thanks to the availability of many different types of modules in both the Moodle core and in the official plugin repository, it was possible to implement various types of activities. The additional modules that were installed and made available in the platform were:

- Dialogue, to allow one-to-one discussions in a forum-like fashion;

- Etherpad lite, to make real time collaboration on text documents possible;

- Open Forum, to provide an alternative to standard Moodle forums, especially in terms of User Experience;

- H5P, to allow the integration of interactive learning activities such as small games and presentations that could be created directly from inside the platform;

- Journal, to add personal notes and open answers to reflection questions that could be reviewed by users, as an alternative to assignments;

- Questionnaire, to be able to collect answers from participants using various types of questions, as an alternative to quiz and feedback modules. ${ }^{11}$

The listed activities were easy to implement in the platform, requiring just the standard Moodle plugin installation procedure and no particular configuration. Apart from minor graphical customization, they did not require particular attention.

On the "multimodal communication" side, the solutions adopted in the VLE development were varied. First of all, especially in compliance with guidelines 1 and 5 of the UDL framework ${ }^{12}$, another plugin was implemented since the beginning of the project, providing all users with the possibility to record audio and video directly from their web browsers, everywhere a text area was present in the various activities proposed. This solution, available via a plugin to the default rich text editor called RecordRTC ${ }^{13}$, later became part of Moodle core (since version 3.6). It enables people who are not familiar, or confident, or at ease in using a keyboard to interact with forums and other writing spaces by simply sharing their thoughts and ideas in the form of oral and gestural transmission. In the same line, the Sketch plugin ${ }^{14}$ was added to the default text editor, to allow expression through drawings, although simple ones.

One last element, also in line with UDL guidelines especially concerning content presentation, was the integration of four other technological solutions that are made available in the whole system via a virtual assistant:

- Text-to-speech synthesis, to allow the direct and independent transformation of written text into audio - this was obtained integrating the ResponsiveVoice. $\mathrm{JS}^{15}$ service into the platform;

- Automatic translation, to make user generated content available in multiple languages obtained by integrating the Google Translate "Website Translator" service ${ }^{16}$;

- High contrast colour schemes, written specifically for this platform but based on the Farfalla Project toolbar [35], to allow the personalization of the user interface appearance;

- Onscreen keyboard, to facilitate writing using different alphabets - based on the open source VirtualKeyboard library ${ }^{17}$

\footnotetext{
${ }^{11}$ All the plugins mentioned in this list are available from the official Moodle plugins repository

${ }^{12}$ Guideline 1 recommends to "Provide options for Perception", while guideline 5 says it is necessary to "Provide options for Expression \& Communication"

${ }^{13}$ https://moodle.org/plugins/atto_recordrtc, last consulted May 9, 2019

${ }^{14} \mathrm{https} / / /$ moodle.org/plugins/atto_sketch, last consulted May 9, 2019

${ }^{15} \mathrm{https} / / /$ responsivevoice.org/, last consulted May 9, 2019

${ }^{16} \mathrm{https}: / /$ translate.google.com/int//en/about/website/, last consulted May 9, 2019 - The feature that allowed to include Google Translate in a website has - at the time of writing - been dropped by Google. This change does not affect existing use of the Website Translator.

${ }^{17}$ https://www.codeproject.com/Articles/17128/JavaScript-VirtualKeyboard, last consulted May 9, 2019
} 


\subsection{Issues and downsides}

Putting together many different technological solutions into one platform represents a huge challenge for usability, and in that sense it was particularly difficult to obtain positive results. This paper is not the place to discuss usability evaluations, yet it is likely that some issues that emerged during the development phase could help other designers and developers in making informed decisions about the implementation of Moodle - and of the plugins available in its official repository - to a superdiverse, multilingual and multicultural environment.

The two main unsolved issues that were faced during the development effort so far are located in the areas of multilingual communication and in the cross-platform compatibility.

In order to facilitate participation for users speaking different languages, the default Moodle language selection menu was activated. Based on a survey of the tongues spoken by the participants, a list of 37 different languages was compiled and the corresponding language packs were installed in the ISOTIS VLE. The default method included in Moodle to specify that content (or part of it) is multilingual is based on the use of special HTML tags. As making this functionality available to all users was important in the logic of the project, another option was investigated, involving the use of the MultiLanguage Content (v2) $)^{18}$ filter plugin, in combination with Atto Multilanguage plugin ${ }^{19}$. This improved usability dramatically, but two issues arose:

1 The method could cause unexpected results especially in complex texts, in cases where the plugin markup (requiring to insert tags like \{mlang en\} to identify a section of text to be displayed when the platform visualization language was English) conflicted with the underlying HTML code; this issue can be solved most of the time by manually reviewing the source code of a piece of content, but this means that HTML knowledge is a (hidden) requirement;

2 The method was not directly available in titles, it was mainly designed for larger texts, typically input via a rich-text editor. It was still possible to manually enter translation tags, like in this example:

\{mlang en\}Title in English here\{mlang\} \{mlang it\}Title in Italian here\{mlang\}

The solution seemed to work for titles too, unless it was used with long text or with more than 34 languages: in those cases the text would easily exceed a limitation of characters length set in the application database, rendering the insertion of translated text in titles impossible. A solution was identified also in this case, based on the definition of placeholder codes that could be configured in another area of the platform and reused where necessary, but this represented a huge burden for usability, plus it required some administrative permissions.

Another issue that was encountered is related to the way Moodle, and especially the above mentioned RecordRTC plugin, manages audio and video inputs: as the software and its community of developers and users fully embrace the ideas of Open Source software, the technological stack used for the development of such a feature is also based on open, web-based solutions, namely the WebRTC project ${ }^{20}$. This particular technology is supported by most browsers and by mobile platforms such as Google Android and Apple iOS. Unfortunately, at the present time iOS support is not full, and specifically the web browser rendering engine used in this Operating System is not compliant with the implementation available for Moodle. This same problem afflicts Apple Safari and Microsoft Edge, the default browsers in Apple MacOS and in Microsoft Windows, respectively. This makes the audio-video recording feature unavailable on those specific platforms. These limitations do not apply just to recording, but also to the audio and video playback features: RecordRTC uses OGG as a format to store audio files and WEBM for videos, but those formats are not directly supported at least by iOS at the time of writing.

\section{CONCLUSIONS}

The paper described the ISOTIS project, its theoretical underpinnings, and specifically the issues encountered during the development of a VLE platform inside its context. The main requirement set by the project is inclusiveness in multilingual contexts, and the approach chosen to face such a challenge

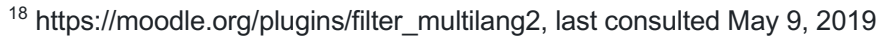

${ }^{19} \mathrm{https} / / /$ moodle.org/plugins/atto_multilang2, last consulted May 9, 2019

${ }^{20} \mathrm{https}: / /$ webrtc.org/, last consulted May 9, 2019
} 
is that of Universal Design for Learning. The solutions discussed here proved either to be viable - in the sense of being manifestly useful and straightforward in their implementation - or to be causing further issues, with negative effects on the overall usability of the platform.

In the specific case of the translation management system, it became evident that the solutions provided by the chosen platform, although perfectly functioning, were not entirely efficient. This was especially true when it came to using them in highly varied situations, with more than a small amount of different languages to manage. This is not generalizable and is only valid in the context of Moodle and of the plugins provided by the community around it in the official repository, yet it makes clear how efforts in terms of multilingual support can be significantly hindered by wrong design choices in the tools that can be used in educational contexts.

The second issue discussed here is more generally connected to the proliferation of formats and platforms that makes the digital world a place where - sometimes unexpectedly - users can experiment barriers and situations of exclusion that depend on something that is not easy to foresee or to control. Besides proper testing, with and without real users, those issues need to be addressed by carefully choosing the technologies and the standards to adopt, without giving anything for granted.

Further research in this area will concentrate on investigating the effects of the platform with real users, and in determining the efficacy of the solutions presented here in the light of their feedback, their preferences and their learning achievements.

\section{ACKNOWLEDGEMENTS}

This work was funded by European Union Horizon 2020, Grant Agreement No. 727069.

\section{REFERENCES}

[1] C. Dustmann, T. Frattini, and G. Lanzara, "Educational achievement of second-generation immigrants: an international comparison," Econ. Policy, vol. 27, no. 69, pp. 143-185, Jan. 2012.

[2] A. Di Bartolomeo, "Explaining the gap in educational achievement between second-generation immigrants and natives: the Italian case," J. Mod. Ital. Stud., vol. 16, no. 4, pp. 437-449, Sep. 2011.

[3] M. A. Santos, A. Godás, M. J. Ferraces, and M. Lorenzo, "Academic Performance of Native and Immigrant Students: A Study Focused on the Perception of Family Support and Control, School Satisfaction, and Learning Environment," Front. Psychol., vol. 7, Oct. 2016.

[4] F. Heckmann and D. Schnapper, "The Integration of Immigrants in European Societies: National Differences and Trends of Convergence," in Integration Policies towards Immigrants and Their Descendants in the Netherlands, 2003, pp. 165-184.

[5] Robert D. Putnam, "E Pluribus Unum: Diversity and Community in the Twenty-first Century The 2006 Johan Skytte Prize Lecture," Scan. Polit. Stud., vol. 30, no. 2, pp. 137-174, 2008.

[6] S. Vertovec, "Super-diversity and its implications," Ethn. Racial Stud., vol. 30, no. 6, pp. 10241054, 2007.

[7] G. Valdés, "The World Outside and Inside Schools: Language and Immigrant Children," Educ. Res., vol. 27, no. 6, pp. 4-18, 1998.

[8] I. Gogolin, "The Challenge of Super Diversity for Education in Europe," Educ. Inq., vol. 2, no. 2, pp. 239-249, Jun. 2011.

[9] Eurostat, Indicators of Immigrant Integration. A Pilot Study. 2011.

[10] OECD, "PISA - Untapped Skills: Realising the Potential of Immigrant Students," 2012.

[11] P. Leseman and C. VanTuijl, "Cultural diversity in early literacy: Findings in Dutch studies," in Handbook of early literacy research (Vol. 2), D. Dickinson and S. Neuman, Eds. New York: Guilford Press, 2006, pp. 221-228.

[12] A. Lareau, Unequal Childhoods: Class, Race, and Family Life. 2003. 
[13] M. Vandenbroeck, "Ethnic diversity and social inclusion in ECCE in Europe," in Investing against Evidence. The Global State of Early Childhood Care and Education, no. January, Unesco Publishing, 2015, pp. 115-118.

[14] M. Crul, "Super-diversity vs. assimilation: how complex diversity in majority-minority cities challenges the assumptions of assimilation," J. Ethn. Migr. Stud., vol. 42, no. 1, pp. 54-68, 2016.

[15] G. Brunello and D. Checchi, "Does school tracking affect equality of opportunity? New international evidence," Econ. Policy, vol. 22, no. 52, pp. 782-861, Oct. 2007.

[16] U. Bronfenbrenner, Understanding Children in Context: The Ecological Model of Human Development. 1979.

[17] U. Bronfenbrenner and S. J. Ceci, "Nature-nurture reconceptualized in developmental perspective: A bioecological model.," Psychol. Rev., vol. 101, no. 4, pp. 568-586, 1994.

[18] U. Bronfenbrenner and P. A. Morris, "The bioecological model of human development," in Handbook of child development: Vol. 1. Theoretical models of human development, R. M. Lerner, Ed. Hoboken, NJ: Wiley, 2006, pp. 793-828.

[19] P. P. M. Leseman and D. C. van den Boom, "Effects of quantity and quality of home proximal processes on Dutch, Surinamese-Dutch and Turkish-Dutch pre-schoolers' cognitive development," Infant Child Dev., vol. 8, no. 1, pp. 19-38, Mar. 1999.

[20] K. A. Magnuson, M. K. Meyers, C. J. Ruhm, and J. Waldfogel, "Inequality in Preschool Education and School Readiness," Am. Educ. Res. J., vol. 41, no. 1, pp. 115-157, Jan. 2004.

[21] A. Fernald, V. A. Marchman, and A. Weisleder, "SES differences in language processing skill and vocabulary are evident at 18 months," Dev. Sci., vol. 16, no. 2, pp. 234-248, Mar. 2013.

[22] H. Mulder, H. Hoofs, J. Verhagen, I. van der Veen, and P. P. M. Leseman, "Psychometric properties and convergent and predictive validity of an executive function test battery for two-yearolds," Front. Psychol., vol. 5, Jul. 2014.

[23] J. Cadima, A. M. Gamelas, M. McClelland, and C. Peixoto, "Associations Between Early Family Risk, Children's Behavioral Regulation, and Academic Achievement in Portugal," Early Educ. Dev., vol. 26, no. 5-6, pp. 708-728, Jul. 2015.

[24] K. Magnuson and H. Shager, "Early education: Progress and promise for children from lowincome families," Child. Youth Serv. Rev., vol. 32, no. 9, pp. 1186-1198, Sep. 2010.

[25] D. Rose and A. Meyer, Teaching Every Student in the Digital Age: Universal Design for Learning. Alexandria, VA: ASCD, 2002.

[26] K. A. Lowrey, A. Hollingshead, K. Howery, and J. B. Bishop, "More Than One Way: Stories of UDL and Inclusive Classrooms," Res. Pract. Pers. with Sev. Disabil., p. 154079691771166, 2017.

[27] R. Mace, Universal Design, Barrier Free Environments for Everyone. Los Angeles: Designers West, 1985.

[28] M. Pearson, "Modeling Universal Design for Learning Techniques to Support Multicultural Education for Pre-Service Secondary Educators," Multicultural Education, vol. 22. pp. 27-34, 2015.

[29] D. Van Garderen and C. Whittaker, "Planning Differentiated, Multicultural Instruction for Secondary Inclusive Classrooms," Except. Child., vol. 38, no. 3, pp. 12-21, 2003.

[30] A. Calvani, R. Trinchero, and G. Vivanet, "Nuovi orizzonti della ricerca scientifica in educazione. Raccordare ricerca e decisione didattica: il Manifesto S.Ap.I.E.," ECPS - Educ. Cult. Psychol. Stud., no. 18, pp. 311-339, Dec. 2018.

[31] N. Cavus and T. Zabadi, "A Comparison of Open Source Learning Management Systems," Procedia - Soc. Behav. Sci., vol. 143, pp. 521-526, Aug. 2014.

[32] N. Cavus, "Selecting a learning management system (LMS) in developing countries: Instructors' evaluation," Interact. Learn. Environ., vol. 21, no. 5, pp. 419-437, 2013.

[33] S. Krishnamurthy, "A managerial overview of open source software," Bus. Horiz., vol. 46, no. 5, pp. 47-56, Sep. 2003. 
[34] L. Morgan and P. Finnegan, "Benefits and drawbacks of open source software: An exploratory study of secondary software firms," IFIP Int. Fed. Inf. Process., vol. 234, pp. 307-312, 2007.

[35] A. Mangiatordi and H. Singh Sareen, "Farfalla project: browser-based accessibility solutions," in Proceedings of the International Cross-Disciplinary Conference on Web Accessibility - W4A '11, 2011, p. 1. 